\title{
OUTCOME OF MEDICALLY (METHOTREXATE) MANAGED CASES OF UNRUPTURED ECTOPIC TUBAL PREGNANCY - AN ORIGINAL CASE STUDY
}

\author{
Vengadeswari Ramakrishnan', Kavitha Paranthaman ${ }^{2}$
}

${ }^{1}$ Associate Professor, Department of Obstetrics and Gynaecology, Government Villupuram Medical College, Villupuram. ${ }^{2}$ Assistant Professor, Department of Obstetrics and Gynaecology, Government Villupuram Medical College, Villupuram.

\section{ABSTRACT}

\section{BACKGROUND}

Ectopic pregnancy is defined as the implantation of fertilised ovum or blastocyst anywhere other than in a normal uterine cavity. This includes tubal pregnancies and non-tubal pregnancies involving the ovary, cornual region of the uterus, rudimentary uterine horn, the abdominal cavity and in the cervix. Ectopic pregnancy can lead to massive haemorrhage, infertility or death. With earlier diagnosis, both maternal survival and conservation of reproductive capacity are enhanced.

\section{MATERIALS AND METHODS}

All patients admitted to Institute of Obstetrics and Gynaecology with diagnosis of unruptured ectopic pregnancy managed medically between August 2011 and July 2012 were included in the study. The diagnosis of tubal pregnancy was made using both Transvaginal Sonography (TVS) and measurement of $\beta$-HCG level. The patients who were managed medically with methotrexate were categorised into 5 groups for followup base on initial $\beta$-HCG levels. Single dose methotrexate regimen was followed for patients with $\beta$-hCG levels ranging from $200 \mathrm{mIU} / \mathrm{mL}$ to $6984 \mathrm{mIU} / \mathrm{mL}$. Multiple dose methotrexate regimens were followed for patients with $\beta$-hCG levels more than $7500 \mathrm{mIU} / \mathrm{mL}$.

\section{RESULTS}

Total numbers of cases of ectopic tubal pregnancy from August 2011 to July 2012 were 119. Out of these 119 cases, 39 were managed medically during the same period (32.7\%). In this study, age of the patient's ranges from 19 to 36 years with mean age of 27.03 years, $21 \%$ were primigravida and $10 \%$ were second gravida and 17 out of total 39 had an associated risk factors. The commonest risk factor was found to be medical termination of pregnancy (17.9\%). Among the patients studied, gestational ranged from 28 to 70 days and the maximum number of patients had their $\beta$-hCG levels between $200-2500 \mathrm{mIU} / \mathrm{mL} ; 56.4 \%$ of the patients had their adnexal mass size between $2-3 \mathrm{cms}$. Out of 39 patients 29 were managed with single dose of intramuscular methotrexate injection, whereas 5 patients were given multiple doses of methotrexate and 5 patients were not given any dose of methotrexate as they presented with very low levels of B-hCG level.

\section{CONCLUSION}

Complete resolution was seen in all cases of single dose methotrexate regimen whose mean initial $\beta$-hCG was $2683 \mathrm{mIU} / \mathrm{mL}$, adnexal mass $<2 \mathrm{cms}$ and amenorrhoea $<42$ days. Statistically significant association was seen between the initial $\beta$-hCG levels and with outcome of treatment. In cases managed with multiple dose methotrexate regimen, complete resolution was seen in those having mean initial $\beta$-hCG of $7688.4 \mathrm{mIU} / \mathrm{mL}$ and adnexal mass size $<2 \mathrm{cms}$.

KEYWORDS: Ectopic, Methotrexate, $\beta$-hCG.

HOW TO CITE THIS ARTICLE: Ramakrishnan V, Paranthaman K. Outcome of medically (methotrexate) managed cases of unruptured ectopic tubal pregnancy - an original case study. J. Evolution Med. Dent. Sci. 2016;5(88):6574-6579, D0I: 10.14260/Jemds/2016/1486

\section{BACKGROUND \\ Ectopic pregnancy is defined as the implantation of fertilised ovum or blastocyst anywhere other than in a normal uterine cavity. This includes tubal pregnancies and non-tubal pregnancies involving the ovary, $1,2,3,4,5$ cornual region of the uterus, rudimentary uterine horn, the abdominal cavity and in the cervix.6,7}

Financial or Other, Competing Interest: None.

Submission 15-09-2016, Peer Review 22-10-2016,

Acceptance 28-10-2016, Published 03-11-2016.

Corresponding Author:

Dr. Vengadeswari Ramakrishnan,

H91, G3, Sea View Apartment,

First Sea Ward Road,

Valmeegi Nagar,

Chennai-600041.

E-mail:dhasaraven@yahoo.co.in

DOI: $10.14260 /$ jemds $/ 2016 / 1486$
This abnormally implanted gestation grows and draws its blood supply from the site of abnormal implantation. As the gestation enlarges, it creates the potential for organ rupture, because only the uterine cavity is designed to expand and accommodate foetal development. Ectopic pregnancy can lead to massive haemorrhage, infertility or death.

This study evaluates the outcome of medically managed cases of unruptured tubal ectopic pregnancies using intramuscular methotrexate and also to assess the association of outcome with the following parameters:

1. Initial $\beta$-hCG levels.

2. Adnexal mass size.

3. Period of amenorrhoea.

4. Presence or absence of cardiac activity.

\section{MATERIALS AND METHODS}

All patients admitted to Institute of Obstetrics and Gynaecology with diagnosis of unruptured ectopic pregnancy managed medically between August 2011 and July 2012 were 
included in the study. The diagnosis of tubal pregnancy was made using both Transvaginal Sonography (TVS) and measurement of $\beta$-hCG level. Ectopic pregnancy was diagnosed when adnexal mass or extrauterine tubal gestational sac without intrauterine gestation was observed with TVS and when patients had inappropriately rising $\beta$-hCG levels. Patients who were haemodynamically unstable and who refused medical treatment with MTX and close follow-up treated surgically.

The patients who were managed medically with methotrexate were categorised into 5 groups for followup based on initial $\beta$-hCG levels.

$(<2500) \mathrm{mIU} / \mathrm{mL}$ and $(7500-10000) \mathrm{mIU} / \mathrm{mL}$ patients with very low $\beta$-hCG levels $(<200 \mathrm{mIU} / \mathrm{mL})$ were managed expectantly.

Single dose methotrexate regimen was followed for patients with $\beta$-hCG levels ranging from $200 \mathrm{mIU} / \mathrm{mL}$ to 6984 $\mathrm{mIU} / \mathrm{mL}$.

Multiple dose methotrexate regimen was followed for patients with $\beta$-hCG levels more than $7500 \mathrm{mIU} / \mathrm{mL}$.

Before treatment with methotrexate, patients were counselled about the benefits and risk of treatment, the expected course and duration of treatment, and the importance of follow-up. Blood grouping and typing was done for all the patients and anti-D immunoglobulin (250 IU or 50 micrograms) administered to all $\mathrm{Rh}$ negative mothers. All patients gave their informed consent before beginning the treatment.

\section{Inclusion Criteria}

- Patients who came with amenorrhoea, abdominal pain, bleeding or spotting $\mathrm{P} / \mathrm{V}$ and were diagnosed to have ectopic pregnancy after doing:

1. Urine Pregnancy Test.

2. Transvaginal sonography.

3. Serum $\beta$-HCG Levels.

- Haemodynamically stable patients without active bleeding or signs of haemoperitoneum.

- $\quad$ Patients desiring future fertility.

- Patients willing for followup care.

- No contraindication to MTX therapy.

\section{Exclusion Criteria}

- Haemoperitoneum or haemodynamically unstable patients.

- Contraindication to MTX therapy.

1. Breastfeeding.

2. Over evidence of immunodeficiency.

3. Alcoholism/other chronic liver disease.

4. Pre-existing blood dyscrasias.

5. Known sensitivity to methotrexate.

6. Active pulmonary disease.

7. Peptic ulcer disease.

8. Any chronic renal disorder.

\section{Single Dose Regimen}

After doing haemoglobin level, total count/differential count, platelet count, renal function tests, liver function tests and Serum $\beta$-HCG was documented. On Day 1 , single intramuscular dose $(1 \mathrm{mg} / \mathrm{kg})$ of methotrexate was given. On Day 4 and 7 after the injection, $\beta$-hCG levels were measured. Patients received a repeat injection of MTX on Day 7, if their $\beta$-hCG levels failed to decline by at least $15 \%$ between Day 4 and 7 and the protocol was restarted as Day 1 . If the repeat $\beta$-hCG level on Day 7 showed more than $15 \%$ fall when compared to Day 4, weekly followup was done till levels $<5 \mathrm{mIU} / \mathrm{mL}$. A successful response to MTX was defined as the resolution in the $\beta$-hCG level $<5 \mathrm{mIU} / \mathrm{mL}$. However, patients who required second dose of MTX due to inadequate fall in $\beta$-hCG levels by Day 7 were considered as failure of single dose regimen, but successful medical treatment. With signs of tubal rupture, surgery was done.

All continuous variables are expressed as the mean \pm SD. For statistical analysis, T-test and Chi-square test were used.

\section{Multi-Dose Regimen}

As in single dose regimen these patients also underwent investigations, namely Haemoglobin levels, Total Count/Differential Count, Platelet count, Kidney function tests, LFT and serum $\beta$-hCG levels. Inj. Methotrexate $(1 \mathrm{mg} / \mathrm{kg}$ ) intramuscular was given on Day 1, 2, 5 and 7 of the protocol followed by Inj. Leucovorin $(0.1 \mathrm{mg} / \mathrm{kg})$ on Day 2, 4, 6 and 8 . Serum $\beta$-hCG levels were repeated every alternate day from Day 3 onwards.

Complete blood and platelet count along with renal and liver function tests were repeated at the end of protocol to see any adverse effects of the drug. Weekly titres of $\beta$-hCG were done till they were $<5 \mathrm{mIU} / \mathrm{mL}$. However, treatment was declined when a decline of $>15 \%$ was observed in two consecutive counts of serum $\beta$-hCG after Day 3 or after completion of four dose of methotrexate (MTX). These patients were also followed up with weekly titres of $\beta$-hCG.

\section{Expectant Management}

With serial $\beta$-hCG measurements twice weekly was done to ensure a rapidly decreasing $\beta$-hCG level and transvaginal ultrasound examinations weekly to see the decrease in the size of adnexal mass by 7 days. Thereafter, weekly $\beta$-hCG and transvaginal ultrasound examinations were advised till serum $\beta$-hCG levels were $<5 \mathrm{mIU} / \mathrm{mL}$.

\section{OBSERVATIONS AND RESULT}

Total numbers of cases of ectopic tubal pregnancy from August 2011 to July 2012 were 119 . Out of these 119 cases, 39 were managed medically during the same period (32.7\%).

\section{Age Distribution}

In this study, age of the patients ranges from 19 to 36 years with mean age of 27.03 years \pm 5.50 SD.

\section{Gravidity Distribution}

Among the patients studied, 21\% were primigravida and $10 \%$ were second gravida.

\section{Associated Risk Factors for Ectopic Pregnancy \\ Various associated factors, which increases the risk of ectopic pregnancies were studied in 39 cases; 17 out of total 39 had an associated risk factors and the commonest risk factor was found to be medical termination of pregnancy $(17.9 \%)$ followed by previous LSCS (12.8\%).}

\section{Gestational Age Distribution}

Among the patients studied, gestational ranged from 28 to 70 days with mean gestational age of 48.2 days \pm 9.03 SD. 
Maximum numbers of patients at gestational age between 43 to 56 days, i.e. $56.4 \%$.

\section{$\boldsymbol{\beta}$-hCG Levels at Presentation}

In the study group, the distribution of $\beta$-hCG levels were studied. The maximum number of patients had their $\beta$-hCG levels between $200-2500 \mathrm{mIU} / \mathrm{mL}$.

\section{Adnexal Mass Size at Presentation}

Maximum number of patients, i.e. $56.4 \%$ had their adnexal mass size between 2 - $3 \mathrm{cms}$.

\section{Methotrexate Regimen Distribution}

Out of 39 patients 29 were managed with single dose of intramuscular methotrexate injection $1 \mathrm{mg} / \mathrm{kg}$, whereas 5 patients were given multiple doses of methotrexate as they presented with $\beta$-hCG level more than $750 \mathrm{mIU} / \mathrm{mL} ; 5$ patients were not given any dose of methotrexate as they presented with very low levels of $\beta$-hCG level, i.e. $<200 \mathrm{mIU} / \mathrm{mL}$.

\section{Single Dose Regimen - Outcome of Treatment}

Of the 29 patients treated with single dose regimen 22 (76\%) resolved with single dose, $3(10.3 \%)$ required repeat second dose, and $4(13.7 \%)$ were managed surgically before Day 7 due to severe pain abdomen or evidence of haemoperitoneum.

\section{Final Outcome in Association with Initial $\beta$-hCG Levels} Among the patients given single dose methotrexate, 18 had $\beta$ hCG levels lesser than $2500 \mathrm{mIU} / \mathrm{mL}, 4$ had levels between $2500-5000 \mathrm{mIU} / \mathrm{mL}$ and 3 patients had $\beta$-hCG levels from $5000-7500 \mathrm{mIU} / \mathrm{mL}$. Among the 5 patients treated with multiple dose regimen, 5 patients presented with $\beta$-hCG levels between $7500-10000 \mathrm{mIU} / \mathrm{mL}$. The association of outcome with $\beta$-hCG levels is shown in Table 1 ( $p$ value $<0.05$ significant):

$\mathrm{P}$ value $<0.05$, hence statistically significant association was found between initial $\beta$-hCG levels and outcome of treatment with methotrexate in single dose regimen.

\begin{tabular}{|c|c|c|c|c|c|c|c|}
\hline \multirow{2}{*}{\multicolumn{3}{|c|}{ Methotrexate Regimen }} & \multicolumn{5}{|c|}{ Outcome } \\
\hline & & & \multirow{2}{*}{$\frac{\text { Resolved }}{5}$} & \multirow{2}{*}{$\begin{array}{c}\% \\
100 \%\end{array}$} & \multirow{2}{*}{$\begin{array}{c}\text { Underwent Surgery } \\
-\end{array}$} & \multirow{2}{*}{$\%$} & \multirow{2}{*}{$\frac{\text { Total }}{5}$} \\
\hline Fynectant Man & Dav $1 \mathrm{hCC}$ level $\sigma$ c & Less than 200 & & & & & \\
\hline Expectant vanagement & Day 1 ncu revergps & Total & 5 & & & & 5 \\
\hline \multirow{4}{*}{ Single Dose Regimen } & \multirow{4}{*}{ Day 1 hCG level gps } & $201-2500$ & 18 & $62 \%$ & 0 & - & 18 \\
\hline & & $2501-5000$ & 4 & $13.7 \%$ & 0 & - & 4 \\
\hline & & $5001-7500$ & 3 & $10.3 \%$ & 4 & $13.7 \%$ & 7 \\
\hline & & Total & 25 & & 4 & & 29 \\
\hline \multirow{2}{*}{ Multiple Dose Regimen } & \multirow{2}{*}{ Day 1 hCG level gps } & $7501-10000$ & 2 & $40 \%$ & 3 & $60 \%$ & 5 \\
\hline & & Total & 2 & & 3 & & 5 \\
\hline
\end{tabular}

\section{Outcome in Association with Adnexal Mass Size}

Out of 29 patients who were treated with single dose regimen of methotrexate, 11 patients had adnexal size less than $2 \mathrm{cms}$, whereas 18 had adnexal size more than $2 \mathrm{cms}$. Out of 5 patients who were treated with multiple dose regimen, 1 patient had adnexal size less than $2 \mathrm{cms}$, whereas 4 had adnexal mass more than $2 \mathrm{cms}$. The outcome in assocociation with adnexal mass size is shown in Table 2 .

$\mathrm{P}$ value $>0.05$, hence no statistical significance was found between adnexal mass size and outcome of treatment in single dose regimen and multiple dose regimen.

\begin{tabular}{|c|c|c|c|c|c|c|c|}
\hline \multirow{2}{*}{\multicolumn{3}{|c|}{ Methotrexate Regimen }} & \multicolumn{5}{|c|}{ Outcome } \\
\hline & & & \multirow{2}{*}{$\begin{array}{c}\text { Resolved } \\
4\end{array}$} & \multirow{2}{*}{$\begin{array}{c}\% \\
80 \% \\
\end{array}$} & \multirow{2}{*}{$\begin{array}{c}\text { Underwent Surgery } \\
-\end{array}$} & \multirow{2}{*}{$\begin{array}{c}\% \\
- \\
\end{array}$} & \multirow{2}{*}{$\begin{array}{c}\text { Total } \\
4 \\
\end{array}$} \\
\hline \multirow{3}{*}{ Expectant Management } & \multirow{3}{*}{ Mass Size } & $2 \mathrm{cms}$ and less & & & & & \\
\hline & & More than $2 \mathrm{cms}$ & 1 & $20 \%$ & - & - & 1 \\
\hline & & Total & 5 & - & - & - & 5 \\
\hline \multirow{3}{*}{ Single Dose Regimen } & \multirow{3}{*}{ Mass Size } & $2 \mathrm{cms}$ and less & 11 & $38 \%$ & 0 & - & 11 \\
\hline & & More than $2 \mathrm{cms}$ & 14 & $48.2 \%$ & 4 & $13.8 \%$ & 18 \\
\hline & & Total & 25 & - & 4 & - & 29 \\
\hline \multirow{3}{*}{ Multiple Dose Regimen } & \multirow{3}{*}{ Mass Size } & $2 \mathrm{cms}$ and less & 1 & $20 \%$ & 0 & - & 1 \\
\hline & & More than $2 \mathrm{cms}$ & 1 & $20 \%$ & 3 & $60 \%$ & 4 \\
\hline & & Total & 2 & - & 3 & - & 5 \\
\hline
\end{tabular}

\section{Outcome in Association with Period of Amenorrhoea}

Out of 29 patients treated with single dose regimen, 9 patients had amenorrhoea less than 42 days and 16 presented with amenorrhoea more than 42 days and 16 presented with amenorrhoea more than 42 days. Out of 5 patients treated with multiple dose regimen, all patients presented with amenorrhoea more than 42 days. The outcome of treatment in association with period of amenorrhoea is shown in Table 3.

P value $>0.05$, hence no statistical significance was found between period of amenorrhoea and outcome of treatment. 


\begin{tabular}{|c|c|c|c|c|c|c|}
\hline Methotrexate Regimen & & Outcome & & & & \\
\hline & Gestational Age & Resolved & \% & Underwent Surgery & \% & Total \\
\hline Expectant Management & $<42$ days & 2 & $40 \%$ & - & - & 2 \\
\hline & $>42$ days & 3 & $60 \%$ & - & - & 3 \\
\hline & Total & 5 & - & - & - & 5 \\
\hline Single Dose Regimen & $<42$ days & 9 & $31 \%$ & - & - & 9 \\
\hline & $>42$ days & 16 & $55.2 \%$ & 4 & $13.8 \%$ & 20 \\
\hline & Total & 25 & - & 4 & - & 29 \\
\hline Multiple Dose Regimen & $>42$ days & 2 & $40 \%$ & 3 & $60 \%$ & 5 \\
\hline \multicolumn{7}{|c|}{ Table 3. Outcome in Association with Period of Amenorrhoea } \\
\hline
\end{tabular}

\section{DISCUSSION}

This prospective observational study includes all the patients who were diagnosed to have unruptured ectopic pregnancy by Transvaginal Sonography (TVS) and serial $\beta$-hCG levels and were managed medically with methotrexate.

39 patients with unruptured ectopic pregnancy were enrolled in the study and were observed for outcome of treatment with methotrexate.

The mean age of these 39 patients was 27.3 years \pm 5.50 SD. Maximum patients belong to $20-29$ years, i.e. $58.9 \%$. The range was 19 to 36 years.

Mean gravidity of the patients studied was $1.74 \pm$ maximum patients were primi gravidas or second gravida.

Mean gestational age of all patients was 48.2 days \pm 9.03 SD. Maximum number of patients had gestational age between 6 - 8 weeks.

Out of the 39 patients who were included in this study 29 were managed with single dose regimen, 5 were managed with multiple dose regimen and 5 were managed expectantly.

\section{Expectant Management}

5 out of 39 patients who were managed expectantly were not given any dose of methotrexate, as the patients did not have any symptoms or initial $\beta$-hCG levels were very low $(<200$ $\mathrm{mIU} / \mathrm{mL}$ ). They were followed up twice weekly with serial $\beta$ hCG measurements and weekly by transvaginal ultrasound examinations to ensure a rapidly decreasing $\beta$-hCG level (ideally $<50 \%$ of its initial levels within 7 days) and a reduction in the size of adnexal mass by seven days. Thereafter, weekly $\beta$-hCG and transvaginal ultrasound examination were advised until serum $\beta$-hCG levels were less than $5 \mathrm{mIU} / \mathrm{mL}$.

In the present study, 5 patients were managed expectantly. The average initial $\beta$-hCG levels in these 5 patients were found to be $177.6 \mathrm{mIU} / \mathrm{mL} \pm 27.7 \mathrm{SD}$. The average adnexal mass size at presentation was found to be $1.62 \mathrm{cms} \pm .038 \mathrm{SD}$. The average period of amenorrhoea was found to be 47 days \pm 7.87 SD. These patients were managed as per above mentioned protocol and complete resolution was seen in 5 patients with an average time for complete resolution being 19.4 days \pm 12.05 SD.

\section{Methotrexate Regimen for Unruptured Ectopic Pregnancy Single Dose Regimen}

Out of 39 patients, 29 patients were given single dose Inj. Methotrexate $1 \mathrm{mg} / \mathrm{kg}$.

1. Age: The mean age of these 29 patients was $27.27 \mathrm{yrs} . \pm$ 5.11 SDS. Maximum patients belonged to age group of 20 to $29 \mathrm{yrs}$. and the range being 20 to 36 years.
2. Gestational Age: The mean gestational age of these 29 patients was found to be 46.3 days \pm 8.45 SD with range between 30 to 65 days.

3. Gravidity: The mean gravidity amongst these 29 patients was found to be 1.51 .

4. B-hCG levels at presentation: The average initial $\beta$-hCG levels in the patients given with single dose of methotrexate was found to be $2683.02 \mathrm{mIU} / \mathrm{mL}$. The range was found to be between $400 \mathrm{mIU} / \mathrm{mL}$ and 6600 $\mathrm{mIU} / \mathrm{mL}$.

5. Outcome of treatment: 29 patients in this study were given single dose of $1 \mathrm{mg} / \mathrm{kg}$ Inj. Methotrexate intramuscular. However, 25 responded to medical management with methotrexate without any surgical intervention. The end point of treatment, i.e. complete resolution in these patients mean fall of $\beta$-hCG to $<5$ $\mathrm{mIU} / \mathrm{mL}$ without any surgical intervention.

Remaining 4 (13.7\%) went for laparotomy before Day 7 because patients presented with severe abdominal pain or had evidence of haemoperitoneum.

Out of the 25 patients treated with methotrexate 22 (76\%) resolved with single dose of methotrexate, hence successfully managed with single dose of methotrexate; 3 $(10.3 \%)$ required repeat second dose of methotrexate on the $7^{\text {th }}$ Day due to inadequate fall in $\beta$-HCG level $(<15 \%)$ by Day 7 when compared to Day 4 levels of $\beta$-hCG.

6. Outcome of treatment in association with initial $\beta$ hCG levels: Out of the 29 patients treated with single dose methotrexate regimen, 18 had their initial $\beta$-hCG levels < $2500 \mathrm{mIU} / \mathrm{mL}, 4$ had their initial $\beta$-hCG levels between $2500-5000 \mathrm{mIU} / \mathrm{mL}$ and 7 had initial $\beta$-hCG levels between $5000-7500 \mathrm{mIU} / \mathrm{mL}$. Of these $22(75.7 \%)$ patients resolved with single dose of methotrexate. However, $3(10.7 \%)$ patients required repeat second dose of methotrexate, $4(13.7 \%)$ patients went for laparotomy due to inadequate fall in $\beta$-hCG levels or persistent abdominal pain. Statistically significant association was found between initial $\beta$-hCG levels and outcome of treatment. $P$ value is $<0.05$ significant.

7. Outcome in association with adnexal mass size:

Patients presenting with adnexal mass size of less than 2 cms, i.e. 11 (38\%) were successfully treated with single dose regimen and none went for laparotomy. Hence, success rate of single dose regimen was found to be $38 \%$ in those having adnexal mass size less than $2 \mathrm{cms}$. Patients presenting with adnexal mass of $>2 \mathrm{cms}$, i.e. 14 (48.2\%) were successfully treated with single dose regimen and 4 (13.8\%) went for laparotomy either due to severe abdominal pain or evidence of haemoperitoneum. 
No statistical significant association was found between adnexal mass size and outcome of treatment ( $\mathrm{p}$ value $>0.05$ ).

8. Outcome in association with period of amenorrhoea: Of the $9(31 \%)$ patients presenting with period of amenorrhoea less than 42 days, all resolved with single dose regimen - methotrexate therapy. None of the patients in this group went for laparotomy.

Of the $20(69 \%)$ patients presenting with amenorrhoea more than 42 days, 16 (55.2\%) resolved with methotrexate therapy, 4 (13.8) went for laparotomy.

No statistical significant association was found between period of amenorrhoea and outcome of treatment. ( $\mathrm{p}$ value $>0.05$ ).

9. Outcome in Association with Cardiac Activity:

None of the patients in this study had presence of cardiac activity at time of presentation, hence could not be associated with the outcome.

10. Time taken for Resolution: Average time taken for complete resolution of ectopic pregnancy in patients who resolved with single dose of methotrexate was found to be 20.44 days \pm 7.6 SD.

\section{Multi-Dose Regimen for Unruptured Ectopic Pregnancies}

Out of 39 patients, 5 were treated with multiple doses of Inj. Methotrexate $1 \mathrm{mg} / \mathrm{kg}$ IM.

1. Age: Mean age of these 5 patients was found to be 29.6 yrs. $\pm 7.43 \mathrm{SD}$ and the range being 21 to $36 \mathrm{yrs}$.

2. Gravidity: The mean gravidity of the patients in multiple dose regimen was found to be 2.6. The range was found to be between 1 and 4 .

3. Gestational Age: The mean gestational age amongst these patients was found to be 57.4 days \pm 9.68 SD. The range of gestational age was between 43 to 70 days.

4. Initial $\beta$-hCG Levels at Presentation: The mean initial $\beta$ hCG levels amongst these 5 patients was found to be $7688.4 \mathrm{mIU} / \mathrm{mL} \pm 5379.9 \mathrm{SD}$. These patients treated with multiple dose regimen of methotrexate had $\beta$-hCG levels more than $7500 \mathrm{mIU} / \mathrm{mL}$.

5. Outcome of treatment:

Out of the 5 patients treated with multiple dose regimen $2(40 \%)$ resolved with methotrexate, whereas $3(60 \%)$ went for laparotomy due to persistent abdominal pain or evidence of haemoperitoneum.

6. Outcome of Treatment in Association with Initial $\beta$-hCG levels:

The 5 patients who were treated with multiple dose regimen of methotrexate had $\beta$-hCG levels > 7500 $\mathrm{mIU} / \mathrm{mL}$. Out of the 5 patients treated with multiple dose regimen $2(40 \%)$ resolved with methotrexate, whereas $3(60 \%)$ went for laparotomy due to persistent abdominal pain or evidence of haemoperitoneum. The average initial $\beta$-hCG levels in these 3 patients were found to be $9566 \mathrm{mIU} / \mathrm{mL}$.

7. Outcome in Association with Adnexal Mass Size: Of the 5 patients in multiple dose regimen, 1 (20\%) presented with adnexal mass size $<2 \mathrm{cms}$ and treated with multiple dose of methotrexate; $4(80 \%)$ patients presented with adnexal mass size $>2 \mathrm{cms}$, of which 3 $(60 \%)$ went for laparotomy due to severe abdominal pain.
No statistical significant association was found between adnexal mass size and outcome of treatment ( $\mathrm{p}$ value $>$ 0.05).

8. Outcome in Association with Period of Amenorrhoea: of the 5 patients treated with multiple doses of methotrexate, all patients with amenorrhoea $>42$ days $2(40 \%)$ patients resolved with medical treatment, whereas $3(60 \%)$ required surgical intervention.

9. Outcome in Association with Cardiac Activity: None of the patients in this study had presence of cardiac activity at time of presentation, hence could not be associated with the outcome.

10. Time Taken for Resolution: Mean time of resolution of 2 patients out of 5 resolved with multiple doses was 6805 days $\pm 40.3 \mathrm{SD}$.

\section{Summary}

- 39 cases of unruptured ectopic pregnancy, which were managed medically with methotrexate were studied during the period of August 2011 to July 2012.

- Maximum incidence of an unruptured ectopic pregnancy was found amongst the age group of 20 to 29 years.

- Commonest risk factor for ectopic pregnancy found in the study was Medical Termination of pregnancy (17.9\%) followed by previous LSCS being $12.8 \%$.

- $13 \%$ of cases had $\beta$-hCG levels $<200 \mathrm{mIU} / \mathrm{mL}, 46.8 \%$ of cases of unruptured ectopic pregnancies had their initial $\beta$-hCG levels between $200-2500 \mathrm{mIU} / \mathrm{mL}, 41.2 \%$ of cases had $\beta$-hCG levels between 2500 - 10,000 mIU/mL.

- $\quad 56.45$ of cases had adnexal mass size measuring between $2-3 \mathrm{cms}, 41 \%$ of cases presented with adnexal mass size $<2 \mathrm{cms}$, whereas $59 \%$ of cases had initial adnexal mass size of $2 \mathrm{cms}$.

- Of the 39 patients studied, $28.2 \%$ patients had amenorrhoea < 42 days, $56.4 \%$ had amenorrhoea between 43 - 56 days and $15.4 \%$ had amenorrhoea more than 57 days.

\section{Single Dose Regimen}

- In cases managed with single dose methotrexate regimen, $75.7 \%$ resolved with methotrexate when the initial $\beta$-hCG levels were $<5000 \mathrm{mIU} / \mathrm{mL} / 13.7 \%$ underwent surgery when the initial $\beta$-hCG level $>5000 \mathrm{mIU} / \mathrm{mL}$ ( $\mathrm{p}$ value $<$ 0.05 ) significant.

- None of the cases with adnexal mass size $<2 \mathrm{cms}$ with single dose regimen $75.7 \%$ resolved with methotrexate when the initial $\beta$-hCG levels were $<5000 \mathrm{mIU} / \mathrm{mL}$; $13.7 \%$ underwent surgery when the initial $\beta$-hCG level > $5000 \mathrm{mIU} / \mathrm{mL}$ ( $\mathrm{p}$ value, 0.05 ) significant.

- None of the cases with adnexal mass size $<2 \mathrm{cms}$ with single dose regimen went for laparotomy, whereas $13.8 \%$ of cases with mass size $>2 \mathrm{cms}$ went for laparotomy; ( $p$ value $>0.05$ ) not significant.

- $13.8 \%$ of cases with amenorrhoea $>42$ days in single dose methotrexate regimen went for laparotomy, whereas all those with amenorrhoea $<42$ days resolved medically $(\mathrm{p}$ value $>0.05$ ) not significant.

- The association of outcome in relation to presence of cardiac activity could not be studied, as none of the patients with presence of cardiac activity were treated with single dose methotrexate regimen. 


\section{Multiple Dose Regimen}

- In cases managed with multiple dose methotrexate regimen, $40 \%$ resolved with methotrexate when initial $\beta$ hCG levels were between $7500-10000 \mathrm{mIU} / \mathrm{mL}$ and $60 \%$ underwent surgery.

- None of the cases with adnexal mass $<2 \mathrm{cms}$ in multiple dose regimen went in for laparotomy, whereas almost $60 \%$ of patients with adnexal mass $>2 \mathrm{cms}$ when in for laparotomy ( $p$ value $>0.05$ ) not significant.

- In cases managed with multiple dose regimen, $40 \%$ resolved with methotrexate when period of amenorrhoea $>42$ days and $60 \%$ underwent laparotomy when period of amenorrhoea was $>42$ days.

- The association of outcome in relation to presence of cardiac activity could not be studied, as none of the patients with presence of cardiac activity were treated with multiple dose methotrexate regimen.

\section{Expectant Management}

- All patients in expectant management group resolved spontaneously, and average initial $\beta$-hCG level $<200$ $\mathrm{mIU} / \mathrm{mL}$ and time of resolution being 19.4 days.

\section{CONCLUSION}

- Complete resolution was seen in all cases of single dose methotrexate regimen whose mean initial $\beta$-hCG was $2683 \mathrm{mIU} / \mathrm{mL}$, adnexal mass $<2 \mathrm{cms}$ and amenorrhoea $<$ 42 days.

- $\quad$ Statistically significant association was seen between the initial $\beta$-hCG levels and with outcome of treatment. No statistical significance was found between adnexal mass size at presentation, period of amenorrhoea and outcome of treatment in single dose regimen.

- In cases managed with multiple dose methotrexate regimen, complete resolution was seen in those having mean initial $\beta$-hCG of $7688.4 \mathrm{mIU} / \mathrm{mL}$ and adnexal mass size $<2 \mathrm{cms}$.
- No statistically significant association was found between adnexal mass and outcome of treatment in multiple dose regimens.

- However, no association could be assessed between cardiac activity and outcome of treatment, as none of the patients with cardiac activity were treated with methotrexate regimen.

- However, more studies including more number of patients need to be done to assess the correlation between outcome of medical management of unruptured ectopic pregnancy with methotrexate and initial $\beta$-hCG levels, adnexal mass size and period of amenorrhoea and presence of cardiac activity.

\section{REFERENCES}

1. Hage PS, Arnoulk IF, Zarou DM, et al. Laproscopic management of ovarian pregnancy. J Am Assoc Gynecol Laprosc 1994;1(3):283-5.

2. Bouyer J, Coste J, Ferrnandez H, et al. Sites of ectopic pregnancy: a 10 year population based study of 1800 cases. Hum Reprod 2002;17(12):3224-30.

3. Ercal T, Cinar O, Mumcu A, et al. Ovarian pregnancy: relationship to an intrauterine device. Aust N Z J Obstet Gynaecol 1997;37(3):362-4.

4. Speert H. Otto Spiegelberg and his criteria of Ovarian Pregnancy. Obstetric and Gynecologic Milestones, The MacMillan Company, New York 1958:p 255f.

5. Habbu J, Read MD. Ovarian pregnancy successfully treated with methotrexate. J Obstet Gynaecol 2006;26(6):587-8.

6. Parente JT, Ou CS, Levy J, et al. Cervvical pregnancy analysis: a review and report of 5 cases. Obstet Gynecol 1983;62(1):79-82.

7. Laughlin CL, Lee TG, Richards RC. Ultrasonographic diagnosis of cervical ectopic pregnancy. J Ultrasound Med 1983;2(3):137-8. 